\title{
Transcription Factories and Nuclear Organization of the Genome
}

\author{
C.H. Eskiw, N.F. Cope, I. Clay, S. Schoenfelder, T. Nagano, and P. Fraser \\ Laboratory of Chromatin and Gene Expression, The Babraham Institute, Cambridge CB22 3AT, United Kingdom \\ Correspondence: peter.fraser@bbsrc.ac.uk
}

\begin{abstract}
The dynamic compartmental organization of the transcriptional machinery in mammalian nuclei places particular constraints on the spatial organization of the genome. The clustering of active RNA polymerase I transcription units from several chromosomes at nucleoli is probably the best-characterized and universally accepted example. RNA polymerase II localization in mammalian nuclei occurs in distinct concentrated foci that are several-fold fewer in number compared to the number of active genes and transcription units. Individual transcribed genes cluster at these shared transcription factories in a nonrandom manner, preferentially associating with heterologous, coregulated genes. We suggest that the three-dimensional (3D) conformation and relative arrangement of chromosomes in the nucleus has a major role in delivering tissue-specific gene-expression programs.
\end{abstract}

The discovery of long-range intra- and interchromosomal interactions in the nucleus of higher eukaryotes points to a dynamic functional interplay between nuclear architecture and gene expression, challenging the view of transcription as a one-dimensional (1D) process (Schoenfelder et al. 2010a). Individual chromosomes occupy discrete chromosome territories in the 3D space of the nucleus (Bolzer et al. 2005). Increasing evidence suggests that the spatial organization of chromosome territories has a fundamental role in regulating genome function (Fraser and Bickmore 2007; Lanctot et al. 2007). Chromosome territories are arranged nonrandomly, resulting in frequent juxtaposition of "preferred neighbor" chromosomes in specific tissues. These tissue-specific chromosome arrangements have been suggested to have a role in celltype-specific gene-expression patterns (Parada et al. 2004). Chromosomes themselves have a plastic organization, and changes in the spatial relationships between genes and regulatory elements within a chromosome as well as their relationships to their chromosome territories and their neighbors have also been correlated with and, in some cases, directly implicated in gene activation and silencing (Cope et al. 2010). For example, long-range interactions between genes and/or distal regulatory elements are now considered to be an essential component of transcriptional regulation (Carter et al. 2002; Tolhuis et al. 2002; Fraser 2006; Hadjur et al. 2009) and silencing (Grimaud et al. 2006; Sexton et al. 2009). Long-range interactions may also be involved in setting up independent chromatin domains that are insulated from surrounding chromatin effects (Gerasimova et al. 2000; Wallace and Felsenfeld 2007).

Individual genomic regions have often been observed to extend out of their chromosome territories in association with expression of the genes within (Volpi et al. 2000; Chambeyron and Bickmore 2004), and chromosomes can clearly intermingle with their neighbors (Branco and
Pombo 2006), with the potential for interchromosomal regulatory encounters. Why genomic regions change location and where they are going are the subjects of intensive research. It has been suggested that genomic regions may be relocating to specialized subnuclear compartments that favor gene activation or silencing (Sexton et al. 2007). For example, RNA polymerase II (RNAPII) transcription occurs at transcription factories (Jackson et al. 1993; Wansink et al. 1993; Iborra et al. 1996; Osborne et al. 2004; Ragoczy et al. 2006; Mitchell and Fraser 2008), subnuclear compartments that are highly enriched in the active, hyperphosphorylated forms of RNAPII (Iborra et al. 1996).

The widely held view of transcriptional mechanics, of the RNA polymerase complex sliding along a template to generate a transcript, is predominantly based on in vitro biochemical studies with purified or recombinant protein complexes on purified DNA templates. Textbooks are full of descriptions of promoter-bound factors recruiting RNA polymerase II (Pol II), which initiates transcription and then slides along the transcription unit to elongate a transcript. Indeed, single molecules of prokaryotic RNA polymerase have been visualized in vitro, sliding along a fixed DNA template during a 1D diffusional search for a promoter (Kabata et al. 1993; Guthold et al. 1999; Harada et al. 1999) or during transcription (Schafer et al. 1991; Wang et al. 1998; Guthold et al. 1999; Davenport et al. 2000). However, which molecule actually moves in vivo, the polymerase or the DNA, may depend on which offers the least resistance. An anchored polymerase generates considerable pulling force on a DNA template, rotating the double helix in a clockwise manner as it threads the DNA strand through the protein during transcription (Guthold et al. 1999). But it is impossible to know from these in vitro studies what actually happens in vivo (Papantonis et al. 2010). Although the answer to this question may seem trivial, it has profound implications for our understanding of transcription and genome function and can 
only be answered by examining evidence of transcription in the nucleus (Chakalova and Fraser 2010).

\section{TRANSCRIPTIONAL BEHAVIOR OF GENES}

Transcription of most "active" genes is not continuous but appears to occur in pulses or bursts of activity (Wijgerde et al. 1995; Levsky et al. 2002; Chubb et al. 2006; Raj et al. 2006). Live cell studies have shown that individual genes experience fairly brief periods of high transcriptional activity ("on" state) followed by variablelength periods of relative inactivity ("off" state). Normally, we find that essentially all $(\sim 90 \%) \alpha$-globin and $\beta$-globin alleles are transcriptionally active or "on" by RNA fluorescence in situ hybridization (FISH) at the correct developmental stage in erythroid precursor cells (Wijgerde et al. 1995; Gribnau et al. 1998). Transgenic mice in which individual hypersensitive sites of the human $\beta$-globin locus control region (LCR) were deleted displayed a dynamic, on and off pattern of globin gene transcription, suggesting that one role of the LCR is to stabilize the on state (Milot et al. 1996). This is supported by studies examining the effect of deletion of the entire mouse $\beta$-globin LCR (Ragoczy et al. 2006). All cells expressed the globin gene at low levels, but only a fraction of cells displayed RNA FISH signals indicative of ongoing transcription. For most other genes, RNA FISH with intron probes reveals that most alleles of many "active" genes are "off" most of the time (Osborne et al. 2004, 2007; Schoenfelder et al. 2010b). This is true regardless of whether the genes are erythroid specific and/or coordinately regulated with the globin genes, such as $A h s p$ ( $\alpha$-hemoglobin stabilizing protein) and Uros (uroporphyrinogen III synthase; heme biosynthetic enzyme), or unrelated, such as the imprinted genes Igf 2 and Kcnqlot1. Other genes in other tissues behave similarly. Thus, it appears that most "active" genes are transcriptionally silent or "off" most of the time. This, of course, will affect gene-expression levels on a per-cell basis and may be a way that cells regulate gene expression, by dynamically altering the balance between transcription on and off states.

\section{GENES DYNAMICALLY ASSOCIATE WITH TRANSCRIPTION FACTORIES}

Transcription factories are discrete nuclear foci containing high concentrations of the active phosphorylated forms of RNAPII and sites of nascent RNA production (Jackson et al. 1993; Iborra et al. 1996). Examination of individual genes by RNA immunoFISH reveals that signals are invariably associated with RNAPII foci (Osborne et al. 2004, 2007; Ragoczy et al. 2006; Mitchell and Fraser 2008; Schoenfelder et al. 2010b), indicating that essentially all nascent gene transcription occurs in factories, consistent with nascent RNA labeling studies (Wansink et al. 1993). DNA immunoFISH indicates that inactive alleles of "active" genes are generally located away from factories. These results clearly link factory association with active transcription and location away from factories with relative inactivity.
Knowing that chromatin is highly dynamic and that many genes relocate away from their chromosome territories when they become active raises the following questions: Are genes moving to a preassembled transcription factory when active? And if so, do dynamic chromatin movements have a role in the oscillating transcription patterns of genes, by moving in and out of factories? We used the $\beta$-globin gene as a factory reference gene because nearly all alleles are associated with transcription factories in a population of erythroid precursor cells. Double-label RNA FISH analyses reveal that distal actively transcribed genes on the same chromosome can coassociate or share the same transcription factory with the globin genes at very high frequencies. For example, genes tens of mega-bases apart colocalize at factories with the globin genes at frequencies of $40 \%-50 \%$, much higher than could be expected by random localization (Osborne et al. 2004). These results suggested that a substantial proportion of genes move to preassembled transcription factories when they become active. This has long been a prediction of the transcription factory model because in all cells tested the number of factories is substantially lower than the number of active genes and transcription units (Jackson et al. 1998). We verified long-range colocalization by an independent method. Chromosome conformation capture 3C (Dekker et al. 2002; Cope and Fraser 2009) analysis showed specific cross-linking among Ahsp, Uros, and the $\beta$-globin gene (25-30 Mb apart) in formaldehyde-fixed erythroid nuclei and not brain (Osborne et al. 2004). Collectively, these data show that widely separated genes in cis colocalize to discrete nuclear sites specifically during transcription.

We obtained similar results investigating a different set of genes expressed in mouse B-cells (Osborne et al. 2007). Resting mouse B-cells from the spleen express high levels of the immunoglobulin heavy chain gene (Igh) (Bolland et al. 2004). Nearly all Igh loci display RNA FISH signals and are associated with transcription factories, indicating that $I g h$ could be considered a B-cell factory reference gene, like the globin genes in erythroid cells. We induced expression of the immediate early genes (including Fos and $\mathrm{Myc}$ ) in resting mouse B cells and assessed factory association and co-association with the Igh locus (Osborne et al. 2007). Most Fos and Myc alleles were not transcribed (RNA immunoFISH) and were not associated with transcription factories (DNA immunoFISH) in unstimulated B-cells, consistent with low-level expression. However, within $5 \mathrm{~min}$ of induction, the situation had reversed, most $M y c$ and Fos alleles were transcriptionally active and associated with RNAPII foci. The Fos gene, located $\sim 30 \mathrm{Mb}$ from the Igh locus on mouse chromosome 12, showed high levels of colocalization with the Igh RNA FISH signal $(\sim 30 \%)$, similar to distal linked genes in erythroid cells. Surprisingly, activation of the Myc locus on mouse chromosome 15 resulted in $\sim 25 \%$ of the newly active $M y c$ alleles sharing the same factory as the $I g h$ locus. This high level of interchromosomal association at a shared factory suggested two things. First, it supported the view that genes move to preassembled transcription sites when they become active; and, second, that the factory sharing arrangement between the $M y c$ and $I g h$ loci was highly preferential. 
Igh colocalization frequencies with several other unlinked genes were considerably lower. If one considers the volume of the nucleus and an exaggerated volume of an individual RNA FISH signal, the random probability of two signals overlapping within the nucleus would be approximately $1 / 1500$. If one takes a more conservative estimate, that there are only 200 transcription sites per nucleus (Osborne et al. 2004), then the random probability that Myc would enter a factory containing an Igh locus would be about 1/100. Thus, the interchromosomal Myc-Igh transcription association is highly preferential.

$M y c$ and $I g h$ are well known partners in cancer (Rowley 2008). Approximately $80 \%$ of cases of Burkitt's lymphoma and mouse plasmacytoma are associated with chromosomal translocations between Myc and Igh. Our data suggested that preferential coassociations between Igh and $M y c$ at a shared transcription factory could contribute to the frequency of translocations between these loci.

\section{PREFERENTIAL TRANSCRIPTION FACTORY ASSOCIATIONS}

To begin to characterize the basis for preferential associations among heterologous genes at transcription factories, we performed a genome-wide enhanced 4C (e4C) screen (Schoenfelder et al. 2010b) to identify preferred transcription factory partners with the mouse $H b b$ ( $\beta$-globin) and $H b a(\alpha$-globin) loci. We found that the $H b b$ locus on mouse chromosome 7 associated with hundreds of other active gene loci from nearly all mouse chromosomes identifying a transcriptional network. Similarly, e4C using the $\mathrm{Hba}$ locus on mouse chromosome 11 as bait revealed factory associations with hundreds of other gene loci. Although most genes in the two transcription networks were specific to either $\mathrm{Hbb}$ or $\mathrm{Hba}$, the two networks overlapped significantly, with some genes seemingly able to associate preferentially with both $H b b$ and $H b a$.

Bioinformatic analysis of the promoter sequences of the network genes revealed an overrepresentation of sequence motifs containing CACC. We recognized this as a potential binding site for the erythroid Kruppel-like factor (Eklf or Klf1). Comparison of the network genes with genes that are up-regulated or down-regulated by Klf1 revealed significant overrepresentation of genes up-regulated by Klf1 in the network gene lists. This suggested that genes positively regulated by Klf1 may be preferentially sharing factories with the globin genes, and that coregulation by a common transcription factor may be a key feature of the transcription networks. Klf1 is an important factor for $\mathrm{Hbb}$ gene expression (Nuez et al. 1995; Perkins et al. 1995). It binds to the promoters of the definitive globin genes and to various sites within the LCR (Tallack et al. 2010) and regulates the developmental switch between the embryonic/fetal and adult forms of $\beta$-globin (Perkins et al. 1996; Wijgerde et al. 1996). Klf1 also contributes to the regulation of many other erythroid-expressed genes, notably involved in heme biosynthesis and the red cell membrane/ cytoskeleton (Drissen et al. 2005; Tallack et al. 2010). $\mathrm{Klf1}^{--}$mice have severely compromised hemoglobin production, exhibit severe anemia, and die in utero at approx- imately embryonic day 14.5 (E14.5) (Nuez et al. 1995; Perkins et al. 1995).

\section{SPECIALIZED TRANSCRIPTION FACTORIES}

We investigated the location of Klf1 in erythroid precursors via immunofluorescence. Consistent with previous reports (Shyu et al. 2007; Quadrini et al. 2008), we found that most Klf1 is found in the cytoplasm, whereas nuclear Klf1 occurred in a small number of distinct foci. Double labeling with an antibody against RNAPII revealed that nearly all Klf1 nuclear foci overlapped with RNAPII foci (Schoenfelder et al. 2010b). This suggested that $20 \%$ of transcription factories (30-40 per nucleus) were enriched with detectable levels of Klf1. We then asked where transcriptionally active Klf1-dependent and Klf1-independent genes were in relation to these factories. We found that $60 \%-80 \%$ of the transcriptionally active alleles of Klf1dependent genes ( $H b b, H b a, H m b s, E p b 4.9)$ were located in Klf1 factories (Fig. 1, top panel). This suggested that alleles of Klf1-dependent genes had a higher probability to be transcriptionally active if associated with a factory with high levels of Klf1. Active alleles of genes not regulated by Klf1 (Tubb5, Hist1) were found with equal probability in factories with and without Klf1. Collectively, these results show that the majority of active alleles of Klf1-dependent genes are preferentially located in the minority (20\%) of factories with high levels of Klf1, whereas active alleles of genes not regulated by Klf1 had no preference for Klf1-containing factories. A notable exception was the

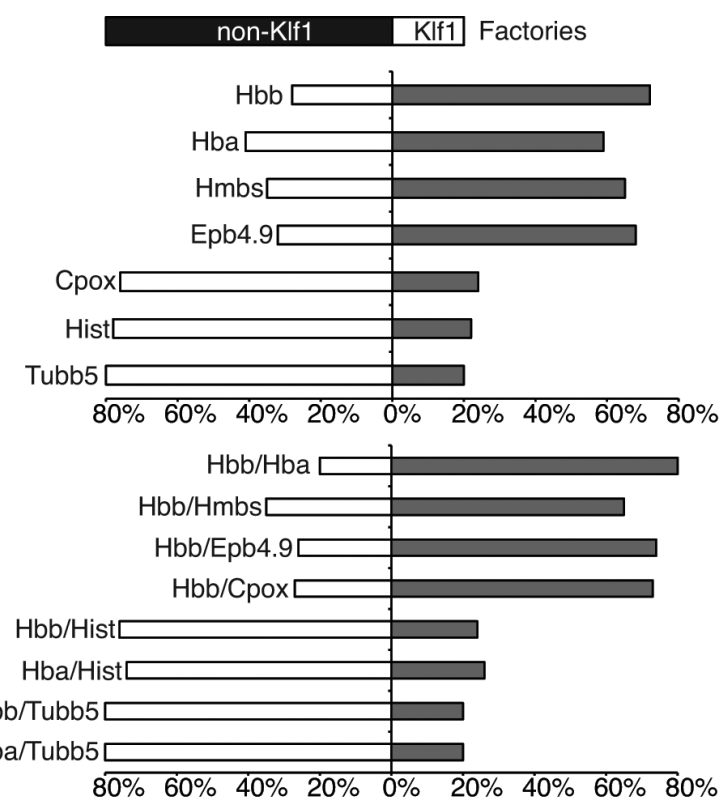

Figure 1. Specialized transcription factories. Bar chart shows the relative localization of RNA FISH signals for several genes at specialized factories with detectable levels of Klf1 versus factories without Klf1. Approximately $20 \%$ of factories in mouse erythroid precursors have high levels of Klf1 (top bar). Individual gene nascent transcript signals are found to varying degrees in Klf1 factories. (Lower panel) Percentages of the type of factory in which colocalizing signals for the two genes listed are found. 
Cpox gene, which encodes a heme biosynthetic enzyme and is partially regulated by Klf1. Active Cpox alleles could be found with almost equal probability in factories with and without Klf1, similar to the Klf1-independent genes.

We then examined pairs of genes by RNA FISH and looked specifically at colocalizing signals in the population (Fig. 1, lower panel). We found that colocalizing pairs of Klf1-dependent genes were found in Klf1 factories to an even higher degree. Of particular relevance were the colocalizing signals of $\mathrm{Hbb}$ and $\mathrm{Cpox}$. Although active Cpox alleles had no preference for Klf1 factories, colocalization with $H b b$ occurred overwhelmingly in Klf1 factories. In contrast, colocalizing signals for $\mathrm{Hbb} / \mathrm{Hist} \mathrm{l}, \mathrm{Hbb} /$ Tubb5, Hba/Hist 1 , and Hba/Tubb5 occurred with equal probability in factories with and without Klf1. In combination, these results show that active alleles of Klf1-dependent genes are preferentially found in factories with high levels of Klf1 and that they preferentially share these specialized factories with other Klf1-dependent genes.

\section{KLF1 ORGANIZES THE ERYTHROID GENOME}

We next verified the nuclear organization of several genes in wild-type and $\mathrm{Klf1}^{--}$fetal liver erythroid cells using 3C (Schoenfelder et al. 2010b). We found that intraand interchromosomal associations among Klfl-dependent genes were specifically disrupted in the Klf $1^{-/}$cells, whereas several long-range interactions not dependent on Klf1 were maintained. By DNA immunoFISH, we found that Klf1-dependent genes are less frequently associated with factories in the knockout cells, reflecting their reduced transcriptional output. Interestingly, we found that the small number of alleles of Klf1-dependent genes that were still active in $\mathrm{Klf1}^{-/}$cells no longer associated with one another at "preferential" frequencies. These results showed that Klf1 is required for the preferential organization of Klf1-dependent genes at shared transcription factories in erythroid precursors.

\section{NONCODING RNAS AND TRANSCRIPTION COMPARTMENTALIZATION}

In contrast to transcription factories, where RNAPII is highly concentrated and multiple active genes come together to produce transcripts, there are distinct regions in the nucleus where RNAPII appears to be functionally excluded. The Xist noncoding RNA is thought to form a repressive compartment that excludes RNAPII and represses $\mathrm{X}$-linked genes in female mammalian cells (Chaumeil et al. 2006). During development, one of the two X chromosomes is inactivated by Xist, which initially accumulates to form a compartment encapsulating mainly nongenic sequence of the future inactive $\mathrm{X}$ chromosome (Clemson et al. 2006). RNAPII is found outside the compartment, and $\mathrm{X}$-linked genes destined for inactivation are eventually drawn into the Xist compartment, coincident with silencing (Chaumeil et al. 2006). Specific repeat sequences on the Xist RNA known as the A repeats (Wutz et al. 2002) are required for the relocation and silencing of X-linked genes. In addition, nuclear scaffold proteins SATB1 and SATB2 (special AT-rich binding proteins) have a crucial role in the silencing process, possibly by holding genes to be silenced within the repressive compartment (Agrelo et al. 2009). Recent results suggest that other ncRNAs, Air and Kcnqlot1, each of which contributes to silencing distinct groups of genes, also appear to form repressive compartments (Nagano et al. 2008; Terranova et al. 2008; Redrup et al. 2009) that recruit genes. These ncRNAs are known to interact with repressive chromatin modifiers such as G9a and Ezh2 (Nagano et al. 2008; Pandey et al. 2008; Zhao et al. 2008), each of which is recruited to chromatin in an ncRNA-dependent manner (Plath et al. 2003; Nagano et al. 2008; Pandey et al. 2008). An emerging concept of silencing by these and possibly other long ncRNAs is through the formation of a compartment enriched with repressive chromatin modifiers, to which target genes are sequestered, thereby reducing chromatin mobility and gene contact with transcription factories.

\section{CONCLUSIONS}

We found that the globin genes ( $H b b$ and $H b a$ ) associate with hundreds of other active genes in transcription factories in mouse erythroid precursors. Obviously, the high numbers of network genes indicate that not all of the associations could be happening simultaneously in a single cell. The transcriptional pulsing of most genes could account for some variability in the associations seen in one cell versus another. However, it is clear from RNA FISH analyses of association frequencies between pairs of genes that every cell is different. Preferential associations between interchromosomal network partner genes and the globin genes occurred at frequencies of $5 \%-10 \%$. These levels of association are much higher than would be expected through random colocalization and are statistically significant but do not point to a need for any one gene to associate with any other specific gene for transcription. Instead, it appears that in most or all erythroid cells, the globin genes are brought into close proximity to a varied subset of their preferred partner genes at the minority of factories that are specialized with high levels of Klf1. Thus, coregulated genes are spatially organized to associate with one another at these specialized factories. The fact that alleles of these genes appear to have a higher probability to be active when associated with a specialized factory suggests that this preferential organization could have a direct effect on the level of expression of these coregulated genes per cell. If a gene is located in a specialized factory containing high concentrations of the factors it needs for initiation, then it may reinitiate more often, thereby stabilizing its presence in the shared factory and increasing its output. In this way, genes and their factors may indirectly cooperate to self-organize into nuclear hotspots that are optimized for their efficient transcriptional output.

We suggest that chromatin mobility is an essential component in transcriptional regulation. Genes must be able to access transcription sites to be transcribed (Papantonis et al. 2010), and the particular character of the factories they have access to within their restricted mobility range may influence the variable levels of expression per cell. 


\section{ACKNOWLEDGMENTS}

We particularly thank and acknowledge the past contributions of Drs. C. Osborne, L. Chakalova, J. Mitchell, T. Sexton, D. Umlauf, and D. Dimitrova. This work was supported by the Medical Research Council and the Biotechnology and Biological Sciences Research Council, UK.

\section{REFERENCES}

Agrelo R, Souabni A, Novatchkova M, Haslinger C, Leeb M, Komnenovic V, Kishimoto H, Gresh L, Kohwi-Shigematsu T, Kenner L, et al. 2009. SATB1 defines the developmental context for gene silencing by Xist in lymphoma and embryonic cells. Dev Cell 16: 507-516.

Bolland DJ, Wood AL, Johnston CM, Bunting SF, Morgan G, Chakalova L, Fraser PJ, Corcoran AE. 2004. Antisense intergenic transcription in $\mathrm{V}(\mathrm{D}) \mathrm{J}$ recombination. Nat Immunol 5: 630-637.

Bolzer A, Kreth G, Solovei I, Koehler D, Saracoglu K, Fauth C, Muller S, Eils R, Cremer C, Speicher MR, et al. 2005. Threedimensional maps of all chromosomes in human male fibroblast nuclei and prometaphase rosettes. PLoS Biol 3: e157. doi: 10.1371/journal.pbio.0030157.

Branco MR, Pombo A. 2006. Intermingling of chromosome territories in interphase suggests role in translocations and transcription-dependent associations. PLoS Biol 4: e138. doi: 10.1371/ journal.pbio. 0040138 .

Carter D, Chakalova L, Osborne CS, Dai YF, Fraser P. 2002. Longrange chromatin regulatory interactions in vivo. Nat Genet 32: 623-626.

Chakalova L, Fraser P. 2010. Organization of transcription. Cold Spring Harb Perspect Biol. 2: a000729. doi: 10.1101/cshperspect. a000729.

Chambeyron S, Bickmore WA. 2004. Chromatin decondensation and nuclear reorganization of the HoxB locus upon induction of transcription. Genes Dev 18: 1119-1130.

Chaumeil J, Le Baccon P, Wutz A, Heard E. 2006. A novel role for Xist RNA in the formation of a repressive nuclear compartment into which genes are recruited when silenced. Genes Dev 20: 2223-2237.

Chubb JR, Trcek T, Shenoy SM, Singer RH. 2006. Transcriptional pulsing of a developmental gene. Curr Biol 16: 1018-1025.

Clemson CM, Hall LL, Byron M, McNeil J, Lawrence JB. 2006 The $\mathrm{X}$ chromosome is organized into a gene-rich outer rim and an internal core containing silenced nongenic sequences. Proc Natl Acad Sci 103: 7688-7693.

Cope NF, Fraser P. 2009. Chromosome conformation capture. Cold Spring Harb Protoc 2009: doi: 10.1101/pdb.prot5137.

Cope NF, Fraser P, Eskiw CH. 2010. The yin and yang of chromatin spatial organization. Genome Biol 11: 204. doi: 10.1186/gb-2010-11-3-204.

Davenport RJ, Wuite GJ, Landick R, Bustamante C. 2000. Singlemolecule study of transcriptional pausing and arrest by $E$. coli RNA polymerase. Science 287: 2497-2500.

Dekker J, Rippe K, Dekker M, Kleckner N. 2002. Capturing chromosome conformation. Science 295: 1306-1311.

Drissen R, von Lindern M, Kolbus A, Driegen S, Steinlein P, Beug H, Grosveld F, Philipsen S. 2005. The erythroid phenotype of EKLF-null mice: Defects in hemoglobin metabolism and membrane stability. Mol Cell Biol 25: 5205-5214.

Fraser P. 2006. Transcriptional control thrown for a loop. Curr Opin Genet Dev 16: 490-495.

Fraser P, Bickmore W. 2007. Nuclear organization of the genome and the potential for gene regulation. Nature 447: 413-417.

Gerasimova TI, Byrd K, Corces VG. 2000. A chromatin insulator determines the nuclear localization of DNA. Mol Cell 6: 10251035.

Gribnau J, de Boer E, Trimborn T, Wijgerde M, Milot E, Grosveld F, Fraser P. 1998. Chromatin interaction mechanism of transcriptional control in vivo. EMBO J 17: 6020-6027.

Grimaud C, Bantignies F, Pal-Bhadra M, Ghana P, Bhadra U, Cav- alli G. 2006. RNAi components are required for nuclear clustering of Polycomb group response elements. Cell 124: 957-971.

Guthold M, Zhu X, Rivetti C, Yang G, Thomson NH, Kasas S, Hansma HG, Smith B, Hansma PK, Bustamante C. 1999. Direct observation of one-dimensional diffusion and transcription by Escherichia coli RNA polymerase. Biophys J 77: 2284-2294.

Hadjur S, Williams LM, Ryan NK, Cobb BS, Sexton T, Fraser P, Fisher AG, Merkenschlager M. 2009. Cohesins form chromosomal cis-interactions at the developmentally regulated IFNG locus. Nature 460: 410-413.

Harada Y, Funatsu T, Murakami K, Nonoyama Y, Ishihama A, Yanagida T. 1999. Single-molecule imaging of RNA polymerase-DNA interactions in real time. Biophys J 76: 709-715.

Iborra FJ, Pombo A, Jackson DA, Cook PR. 1996. Active RNA polymerases are localized within discrete transcription "factories" in human nuclei. J Cell Sci 109: 1427-1436.

Jackson DA, Hassan AB, Errington RJ, Cook PR. 1993. Visualization of focal sites of transcription within human nuclei. EMBO J 12: 1059-1065.

Jackson DA, Iborra FJ, Manders EM, Cook PR. 1998. Numbers and organization of RNA polymerases, nascent transcripts, and transcription units in HeLa nuclei. Mol Biol Cell 9: 1523-1536.

Kabata H, Kurosawa O, Arai I, Washizu M, Margarson SA, Glass RE, Shimamoto N. 1993. Visualization of single molecules of RNA polymerase sliding along DNA. Science 262: 1561-1563.

Lanctot C, Cheutin T, Cremer M, Cavalli G, Cremer T. 2007. Dynamic genome architecture in the nuclear space: Regulation of gene expression in three dimensions. Nat Rev Genet 8: 104-115.

Levsky JM, Shenoy SM, Pezo RC, Singer RH. 2002. Single-cell gene expression profiling. Science 297: 836-840.

Milot E, Strouboulis J, Trimborn T, Wijgerde M, de Boer E, Langeveld A, Tan-Un K, Vergeer W, Yannoutsos N, Grosveld F, et al. 1996. Heterochromatin effects on the frequency and duration of LCR-mediated gene transcription. Cell 87: 105-114.

Mitchell JA, Fraser P. 2008. Transcription factories are nuclear subcompartments that remain in the absence of transcription. Genes Dev 22: 20-25.

Nagano T, Mitchell JA, Sanz LA, Pauler FM, Ferguson-Smith AC, Feil R, Fraser P. 2008. The Air noncoding RNA epigenetically silences transcription by targeting G9a to chromatin. Science 322: $1717-1720$.

Nuez B, Michalovich D, Bygrave A, Ploemacher R, Grosveld F. 1995. Defective haematopoiesis in fetal liver resulting from inactivation of the EKLF gene. Nature 375: 316-318.

Osborne CS, Chakalova L, Brown KE, Carter D, Horton A, Debrand E, Goyenechea B, Mitchell JA, Lopes S, Reik W, et al. 2004. Active genes dynamically colocalize to shared sites of ongoing transcription. Nat Genet 36: 1065-1071.

Osborne CS, Chakalova L, Mitchell JA, Horton A, Wood AL, Bolland DJ, Corcoran AE, Fraser P. 2007. Myc dynamically and preferentially relocates to a transcription factory occupied by Igh. PLoS Biol 5: e192. doi: 10.1371/journal.pbio.0050192.

Pandey RR, Mondal T, Mohammad F, Enroth S, Redrup L, Komorowski J, Nagano T, Mancini-Dinardo D, Kanduri C. 2008. Kcnq1ot1 antisense noncoding RNA mediates lineage-specific transcriptional silencing through chromatin-level regulation. Mol Cell 32: 232-246.

Papantonis A, Larkin JD, Wada Y, Ohta Y, Ihara S, Kodama T, Cook PR. 2010. Active RNA polymerases: Mobile or immobile molecular machines? PLoS Biol 8: e1000419. doi: 10.1371/ journal.pbio. 1000419 .

Parada LA, McQueen PG, Misteli T. 2004. Tissue-specific spatial organization of genomes. Genome Biol 5: R44. doi: 10.1186/gb2004-5-7-r44.

Perkins AC, Sharpe AH, Orkin SH. 1995. Lethal $\beta$-thalassaemia in mice lacking the erythroid CACCC-transcription factor EKLF. Nature 375: 318-322.

Perkins AC, Gaensler KM, Orkin SH. 1996. Silencing of human fetal globin expression is impaired in the absence of the adult $\beta$-globin gene activator protein EKLF. Proc Natl Acad Sci 93: 12267-12271.

Plath K, Fang J, Mlynarczyk-Evans SK, Cao R, Worringer KA, Wang H, de la Cruz CC, Otte AP, Panning B, Zhang Y. 2003. 
Role of histone H3 lysine 27 methylation in X inactivation. Science 300: 131-135.

Quadrini KJ, Gruzglin E, Bieker JJ. 2008. Non-random subcellular distribution of variant EKLF in erythroid cells. Exp Cell Res 314: 1595-1604.

Ragoczy T, Bender MA, Telling A, Byron R, Groudine M. 2006. The locus control region is required for association of the murine $\beta$-globin locus with engaged transcription factories during erythroid maturation. Genes Dev 20: 1447-1457.

Raj A, Peskin CS, Tranchina D, Vargas DY, Tyagi S. 2006. Stochastic mRNA synthesis in mammalian cells. PLoS Biol 4: e309. doi: 10.1371/journal.pbio.0040309.

Redrup L, Branco MR, Perdeaux ER, Krueger C, Lewis A, Santos F, Nagano T, Cobb BS, Fraser P, Reik W. 2009. The long noncoding RNA Kcnq1ot1 organises a lineage-specific nuclear domain for epigenetic gene silencing. Development 136: 525-530.

Rowley JD. 2008. Chromosomal translocations: Revisited yet again. Blood 112: 2183-2189.

Schafer DA, Gelles J, Sheetz MP, Landick R. 1991. Transcription by single molecules of RNA polymerase observed by light microscopy. Nature 352: 444-448.

Schoenfelder S, Clay I, Fraser P. 2010a. The transcriptional interactome: Gene expression in 3D. Curr Opin Genet Dev 20: 127 133.

Schoenfelder S, Sexton T, Chakalova L, Cope NF, Horton A, Andrews S, Kurukuti S, Mitchell JA, Umlauf D, Dimitrova DS, et al. 2010b. Preferential associations between co-regulated genes reveal a transcriptional interactome in erythroid cells. Nat Genet 42: 53-61.

Sexton T, Schober H, Fraser P, Gasser SM. 2007. Gene regulation through nuclear organization. Nat Struct Mol Biol 14: 10491055 .

Sexton T, Bantignies F, Cavalli G. 2009. Genomic interactions: Chromatin loops and gene meeting points in transcriptional regulation. Semin Cell Dev Biol 20: 849-855.

Shyu YC, Lee TL, Wen SC, Chen H, Hsiao WY, Chen X, Hwang J, Shen CK. 2007. Subcellular transport of EKLF and switchon of murine adult $\beta$ maj globin gene transcription. Mol Cell Biol 27: 2309-2323.
Tallack MR, Whitington T, Yuen WS, Wainwright EN, Keys JR, Gardiner BB, Nourbakhsh E, Cloonan N, Grimmond SM, Bailey TL, et al. 2010. A global role for KLF1 in erythropoiesis revealed by ChIP-seq in primary erythroid cells. Genome Res 20: 1052-1063.

Terranova R, Yokobayashi S, Stadler MB, Otte AP, van Lohuizen M, Orkin SH, Peters AH. 2008. Polycomb group proteins Ezh2 and Rnf2 direct genomic contraction and imprinted repression in early mouse embryos. Dev Cell 15: 668-679.

Tolhuis B, Palstra RJ, Splinter E, Grosveld F, de Laat W. 2002. Looping and interaction between hypersensitive sites in the active $\beta$-globin locus. Mol Cell 10: 1453-1465.

Volpi EV, Chevret E, Jones T, Vatcheva R, Williamson J, Beck S, Campbell RD, Goldsworthy M, Powis SH, Ragoussis J, et al. 2000. Large-scale chromatin organization of the major histocompatibility complex and other regions of human chromosome 6 and its response to interferon in interphase nuclei. J Cell Sci 113: $1565-1576$.

Wallace JA, Felsenfeld G. 2007. We gather together: Insulators and genome organization. Curr Opin Genet Dev 17: 400-407.

Wang MD, Schnitzer MJ, Yin H, Landick R, Gelles J, Block SM. 1998. Force and velocity measured for single molecules of RNA polymerase. Science 282: 902-907.

Wansink DG, Schul W, van der Kraan I, van Steensel B, van Driel R, de Jong L. 1993. Fluorescent labeling of nascent RNA reveals transcription by RNA polymerase II in domains scattered throughout the nucleus. J Cell Biol 122: 283-293.

Wijgerde M, Grosveld F, Fraser P. 1995. Transcription complex stability and chromatin dynamics in vivo. Nature 377: 209213.

Wijgerde M, Gribnau J, Trimborn T, Nuez B, Philipsen S, Grosveld F, Fraser P. 1996. The role of EKLF in human $\beta$-globin gene competition. Genes Dev 10: 2894-2902.

Wutz A, Rasmussen TP, Jaenisch R. 2002. Chromosomal silencing and localization are mediated by different domains of Xist RNA. Nat Genet 30: 167-174.

Zhao J, Sun BK, Erwin JA, Song JJ, Lee JT. 2008. Polycomb proteins targeted by a short repeat RNA to the mouse X chromosome. Science 322: 750-756. 


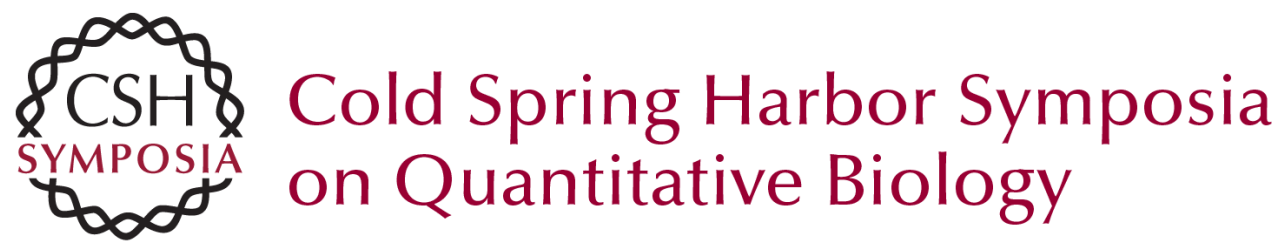

\title{
Transcription Factories and Nuclear Organization of the Genome
}

\author{
C.H. Eskiw, N.F. Cope, I. Clay, et al.
}

Cold Spring Harb Symp Quant Biol 2010 75: 501-506 originally published online April 5, 2011

Access the most recent version at doi:10.1101/sqb.2010.75.046

$\begin{array}{ll}\text { References } & \begin{array}{l}\text { This article cites } 63 \text { articles, } 26 \text { of which can be accessed free at: } \\ \text { http://symposium.cshlp.org/content/75/501.full.html\#ref-list-1 }\end{array}\end{array}$

\section{License}

Email Alerting Receive free email alerts when new articles cite this article - sign up in the box at the Service top right corner of the article or click here.

To subscribe to Cold Spring Harbor Symposia on Quantitative Biology go to:

http://symposium.cshlp.org/subscriptions 